\title{
Two Novel Neuropeptides in Innervation of the Salivary Glands of the Black-Legged Tick, Ixodes scapularis: Myoinhibitory Peptide and SIFamide
}

\author{
LADISLAV ŠIMO ${ }^{1,2}$, DUŠAN ŽITŇAN ${ }^{2}$, and YOONSEONG PARK ${ }^{1,{ }^{*}}$ \\ ${ }^{1}$ Department of Entomology, Kansas State University, Manhattan, Kansas 66506-4004 \\ ${ }^{2}$ Institute of Zoology, Slovak Academy of Sciences, 84506 Bratislava, Slovakia
}

\begin{abstract}
The peptidergic signaling system is an ancient cell-cell communication mechanism that is involved in numerous behavioral and physiological events in multicellular organisms. We identified two novel neuropeptides in the neuronal projections innervating the salivary glands of the blacklegged tick, Ixodes scapularis (Say, 1821). Myoinhibitory peptide (MIP) and SIFamide immunoreactivities were colocalized in the protocerebral cells and their projections terminating on specific cells of salivary gland acini (types II and III). Immunoreactive substances were identified by matrix-assisted laser desorption/ionization-time of flight (MALDITOF) analysis: a 1,321.6-Da peptide with the sequence typical for MIP (ASDWNRLSGMWamide) and a 1,395.7-Da SIFamide (AYRKPPFNGSIFamide), which are highly conserved among arthropods. Genes encoding these peptides were identified in the available Ixodes genome and expressed sequence tag (EST) database. In addition, the cDNA encoding the MIP prepropeptide was isolated by rapid amplification of cDNA ends (RACE). In this report, we describe the anatomical structure of specific central neurons innervating salivary gland acini and identify different neuropeptides and their precursors expressed by these neurons. Our data provide evidence for neural control of salivary gland by MIP and SIFamide from the synganglion, thus leading a basis for functional studies of these two distinct classes of neuropeptides.
\end{abstract}

\section{Keywords}

neuropeptide; myoinhibitory peptide; MIP; SIFamide; MALDI; synganglion; salivary glands

\begin{abstract}
Ticks are obligatory external parasites that feed on the blood of mammals, birds, and reptiles and often transmit pathogenic viruses, Rickettsiae, bacteria, and protozoa. Tick-borne diseases cause substantial economic loss in the animal industry and present risks for human health. The black-legged tick, Ixodes scapularis, transmits the most important tick-borne pathogen, Borrelia burgdorferi, which causes Lyme disease. More than 20,000 new cases are reported per year in the United States, in 46 states. This species also transmits other diseases, including human babesiosis Babesia microti and human granulocytic ehrlichiosis.
\end{abstract}

Salivary secretions of ticks are essential during feeding for manipulation and suppression of host defense responses and might represent key components in the transmission of

\footnotetext{
() 2009 Wiley-Liss, Inc.

* Correspondence to: 123 Warters Hall, Department of Entomology, Kansas State University, Manhattan, KS 66506-4004. ypark@ksu.edu.

Additional Supporting Information may be found in the online version of this article.
} 
pathogens. The salivary glands of the tick consist of numerous spherical acini (also named alveoli) that form grape-like clusters on the branches of excretory ducts. There are three different types of acini in female ticks: I, II, and III. Nongranular (type I) acini, attached to the main salivary duct, do not change size during feeding, whereas other acini increase in size. Granular acini (types II and III) differ in the number and structure of granule-secreting cells; acini III are more peripherally located (Binnington, 1978; Coons and Roshdy, 1973; Krolak et al., 1982). Each type of acinus contains multiple cell types, including different types of secretory and epithelial cells (Balashov et al., 1983; Sauer et al., 1995; Sonenshine, 1993). Studies with transmission electron microscopy have discovered that axon terminals reach the basal region of the acini, indicating that there is neuronal control of the salivary glands (Balashov et al., 1983; Coons and Alberti, 1999). Recently, we have described the neuroanatomy of peptidergic cells in the nervous system, including the neurons and axonal projections that innervate tick salivary glands (Šimo et al., 2009).

Previous immunohistochemical studies have indicated that the tick nervous system is a rich source of diverse neuropeptides related to those that have been identified in insects, crustaceans, and vertebrates (Davis et al., 1994;Šimo et al., 2009; Zhu and Oliver, 1991; Zhu et al., 1995). Periviscerokinin was the first conserved neuropeptide identified in ticks by using matrix-assisted laser desorption/ionization-time of flight (MALDI-TOF) analysis of single neurons (Neupert et al., 2005). Molecular cloning and functional analysis of the Gprotein-coupled receptor for a kinin-like peptide in the southern cattle tick, Boophilus microplus, further suggested that ticks produce multiple neuropeptides and receptors similar to those identified in other arthropods (Holmes et al., 2000, 2003; Taneja-Bageshwar et al., 2006). We recently described the complex neuroendocrine network present in the central and peripheral nervous systems of the hard tick, Rhipicephalus appendiculatus, by using 15 different antibodies that recognize various neuropeptides (Šimo et al., 2009). Four of these antibodies identified peptidergic neurons innervating the main salivary ducts (RFamide and tachykinin) or salivary gland acini [myoinhibitory peptide (MIP) and pigment-dispersing factor (PDF)]. In the present study, we further explored the peptidergic system in the salivary glands of I. scapularis by using MALDI and identified MIP and SIFamide. The genes encoding these peptides were cloned. By using immunohistochemistry and in situ hybridization, we detected coexpression of these neuropeptides in a pair of giant central neurons that projected axons along salivary ducts and terminated on specific acini type II and III.

\section{MATERIALS AND METHODS}

\section{Animals}

Unfed I. scapularis female ticks were obtained from the tick-rearing facility at Oklahoma State University. A colony of $I$. scapularis was kept in polypropylene vials $(9 \times 2.5 \mathrm{~cm})$ with the openings covered by cotton plugs. Each vial contained approximately 30 females and a small sheet $(4 \times 1 \mathrm{~cm})$ of filter paper. These vials were kept in a dark and humid chamber at $4^{\circ} \mathrm{C}$. All experiments described in this study were performed with 1-2-month-old unfed females.

\section{Gene cloning and sequencing}

Search in NCBI trace archives, the EST database and VectorBase (www.vectorbase.org) yielded fragments of DNA sequences encoding putative MIP and SIFamide, respectively. Multiple EST clones encoding SIFamide were found in addition to the gene fragment identified in the genome sequence. To obtain the entire cDNA sequence encoding MIP, we designed primers on the basis of the predicted coding sequences and performed reverse transcript polymerase chain reaction (RT-PCR) and rapid amplification of cDNA ends 
(RACE). The PCR product was cloned into the pGEM-T-easy vector (Promega, Madison, WI) and sequenced. The forward primers used for amplification of the mip gene for $3^{\prime}$ RACE were $5^{\prime}$-GACTGGAACGCGCTGTCAGGC- $3^{\prime}$ and nested $5^{\prime}$ -

AGCGACTGGAATCGCCTCT-3', corresponding to positions 203-223 and 242-260, respectively (Fig. 1B). The reverse primers used for $5^{\prime}$ RACE were $5^{\prime}$ -

TGTGTCGAAGCCGCGCGCTTCC-3' and nested $5^{\prime}$ -

GATCGTTCCAGTGGTTCTCCCG-3' ${ }^{\prime}$, corresponding to positions 430-451 and 386-407, respectively (Fig. 1B). We used the Signal P 3.0 server for annotations of signal peptides (Emanuelsson et al., 2007).

\section{In situ hybridization}

Single-stranded DNA containing digoxygenin dNTP was prepared by using asymmetric PCR. A 248-nucleotide probe for mip (203-451 in Fig. 1B) was generated by using the primers 5'-GACTGGAACGCGCTGTCAGGC-3' (forward) and 5' -

TGTGTCGAAGCCGCGCGCTTCC-3' (reverse). For sifamide, a 190-nucleotide probe (119-308 in Fig. 2B) was made by using the primers 5' -

TGGTGATGGCGGTCATGATGAA-3' (forward) and $5^{\prime}$ -

TGTCGCTACTGCGCGCCATCCT-3’ (reverse). Freshly dissected synganglia were fixed in $4 \%$ paraformaldehyde for 2 hour at room temperature (RT) and washed in PBST (PBS + $0.2 \%$ Triton). The tissues were treated with $10 \mu \mathrm{g} / \mathrm{ml}$ proteinase $\mathrm{K}$ for $\sim 12$ minutes at RT. The reaction was terminated by adding PBST-glycine $(2 \mathrm{mg} / \mathrm{ml}$ glycine) for 5 minutes. Samples were refixed in 4\% paraformaldehyde at RT and washed in PBST three times for 5 minutes each. Prehybridization (10-20 minutes) was followed by hybridization with the respective probes in hybridization solution (HS; $50 \%$ formamide, $5 \times \mathrm{SSC}, 50 \mu \mathrm{g} / \mathrm{ml}$ heparin, $0,1 \%$ Tween 20 , and $100 \mu \mathrm{g} / \mathrm{ml}$ salmon sperm DNA) containing the digoxigeninlabeled probe (Roche Molecular Bio-chemicals) for $\sim 27$ hours at $48^{\circ} \mathrm{C}$ in a humidified chamber. After hybridization, tissues were washed sequentially in $\mathrm{HS}\left(48^{\circ} \mathrm{C}\right)$, HS-PBST (1:1), and PBST twice at RT. After blocking in $100 \mu \mathrm{l}$ 1\% BSA in PBST for 20-30 minutes in RT, the tissues were immediately incubated with sheep antidigoxigenin-AP (alkaline phosphatase; Roche Diagnostick, Germany) at 1:1,000 in PBST overnight at $4^{\circ} \mathrm{C}$. Tissues were washed three times with alkaline phosphatase (AP) buffer (100 mM Tris, $\mathrm{pH} 9.5,50$ $\mathrm{mM} \mathrm{MgCl} 2,100 \mathrm{mM} \mathrm{NaCl}$, and $0.1 \%$ Tween 20). Color was developed by incubation with NBT-BCIP (nitroblue tetra-zolium chloride and 5-bromo-4-chloro-3-indol phosphate; Roche) solution diluted in AP buffer at 1:50. The synganglia were mounted in glycerol and examined under a microscope (Nikon Eclipe E800) with Nomarski differential interference optics. Digital image were captured with a CoolSnap ES2 and enhanced in Adobe Photoshop 7.0.

\section{MALDI-TOF analysis}

Extracts of synganglia and salivary glands were analyzed by a MALDI-TOF mass spectrometer. Ten synganglia and ten pairs of salivary glands were dissected simultaneously in $20 \mu \mathrm{l}$ ice-cold PBS containing $1 \%$ trifluoroacetic acid (TFA; Fisher Scientific, Fair Lawn, $\mathrm{NJ}), \mathrm{pH} 4$. Each tissue was sonicated for 10 seconds in a glass tube and centrifuged at $12,000 \mathrm{~g}$ for 5 minutes at RT. The resulting supernatant was loaded onto an equilibrated ZipTip C18 column (Millipore, Bedford, MA) and eluted with $4 \mu \mathrm{l}$ of a solution containing $0.1 \%$ TFA and $70 \%$ acetonitrile (ACN; Fisher Scientific). Matrix $a$-cyano-4hydroxycinnamic-acid (CHCA; saturated solution in ACN/0.1\% TFA acid 1:2) was freshly prepared. A 4- $\mu \mathrm{l}$ volume of CHCA was mixed with $1 \mu \mathrm{l}$ of eluted sample, and $1 \mu \mathrm{l}$ of the admixture (matrix/sample 4:1) was spotted and dried on a MALDI sample plate at RT.

We used an Ultraflex II TOF/TOF mass spectrometer (Bruker Daltonics, Bremen, Germany). Mass spectra were acquired in reflector positive ion mode. All acquisitions were 
made in manual mode in Flex Control 3.0 software. Tandem mass spectrometry of the two peaks $[\mathrm{M}+\mathrm{H}]^{+} 1,322$ and 1,396 provided partial sequences under laser-induced dissociation (LID) conditions upon analysis with the Flex Analysis 3.0 software package. The obtained partial sequences were compared with the genomic sequence data. For final confirmation of the sequences, we compared the MALDI-TOF results with synthetic MIP (ASDWNRLSGMWamide) and SIFamide (AYRKPPFNGSIFamide). Both synthetic peptides had $\sim 80 \%$ or higher purity on MALDI and HPLC analyses (Bio Basic Inc., Canada).

\section{Whole-mount immunohistochemical staining}

For whole-mount immunohistochemical staining of tick synganglia and salivary glands, we followed a procedure that had previously been successfully used for staining insect endocrine cells (Žitňanová et al., 2001). Ticks were dissected in ice-cold phosphate-buffered saline (PBS: $137 \mathrm{mM} \mathrm{NaCl}, 1.45 \mathrm{mM} \mathrm{NaH}_{2} \mathrm{PO}_{4}, 20.5 \mathrm{mM} \mathrm{Na}_{2} \mathrm{HPO}_{4}, \mathrm{pH}$ 7.2). Isolated synganglia and salivary glands were cleaned from remaining blood and fixed in Bouin's solution (37\% formaldehyde and saturated solution of picric acid 1:3) at RT for 2 hours, followed by a wash in PBS containing 1\% Triton X-100 (PBST). The tissues were then preabsorbed with 5\% normal goat serum (Sigma, St. Louis, MO) in PBST for 10 minutes and subsequently incubated with the either a monoclonal antibody originally raised against Manduca MIP1 (Kim et al., 2006) or polyclonal antiserum for Drosophila SIFamide (Terhzaz et al., 2007) at dilutions of 1:1,000 for 2 days. After three washes with PBST, the tissues were incubated overnight in a mixture of goat anti-mouse IgG conjugated with Alexa 488 and goat anti-rabbit IgG conjugated with Alexa 594 (Molecular Probes, Carlsbad, CA). Stained tissues were washed in PBST and mounted in glycerol containing $300 \mathrm{nM} \mathrm{4} 4^{\prime}, 6^{\prime}$ diamino-2-phenylindole (DAPI; $2 \mu \mathrm{g} \mathrm{ml}^{-1}$; Sigma). Images were observed and acquired with a confocal microscope (Zeiss 510 Meta). Schematic drawings were made in Adobe Photoshop 7.0 or Canvas 8.0.

\section{Antibody characterization}

The immunogen for MIP peptide was ManseMIP1 containing conserved W(6x)Wamide motif (Table 1, Fig. 1A) and for SIFamide peptide was DromeSIFamide having identical sequence to the SIFamide of I. scapularis (Table 1, Fig. 2A). Both antibodies recognized only neuronal cell bodies and projections in I. scapularis synganglion. The immunohistochemistry was validated by similar staining patterns in the in situ hybridizations, particularly for the PcSG neurons. Negative controls included preadsorption with each diluted antibody and $1 \mu \mathrm{M}$ of the corresponding antigen for 24 hours. Preadsorbed antibodies were used for immunohistochemistry as described above. This treatment invariably abolished all immunohistochemical staining.

\section{Nomenclature of peptidergic neurons}

For naming peptidergic neurons, we followed a nomenclature previously used for the hard tick, $R$. appendiculatus, by Šimo et al. (2009). The first two letters refer to the position of each neuron in a specific lobe of the synganglion [cheliceral $(\mathrm{Ch})$, palpal $(\mathrm{Pa})$, stomodeal (St), prothocerebral (Pc), pedal 1-4 $\left(\mathrm{Pd}_{1-4}\right)$, opisthosomal (Os), preoesophageal $(\mathrm{Pe})$ or postoesophageal $(\mathrm{Po})]$, and the letters that follow refer to the anatomical location of the neuron: dorsal (D), ventral (V), anterior (A), posterior (P), medial (M) or lateral (L).

Neurons projecting axons onto the surface of the putative neurohemal periganglionic sheath or lateral segmental organs were considered neurosecretory cells (NC), whereas interneurons (IN) arborized within the synganglion. Neurons innervating acini of salivary glands were labeled SG. 


\section{RESULTS}

\section{MIP and SIFamide in the synganglion}

The staining pattern of MIP in the synganglion of I. scapularis was similar to that previously described for $R$. appendiculatus (Šimo et al., 2009). On the dorsal side, the antibody detected neurons in the protocerebrum (PcAM, PcIN, $\mathrm{PcSG})$, palpal lobe $\left(\mathrm{PaD}_{1,2}\right)$, cheliceral lobe $\left(\mathrm{ChD}_{1-3}\right)$, pedal lobes 2 and $3\left(\mathrm{Pd}_{2} \mathrm{DL}, \mathrm{Pd}_{3} \mathrm{DM}_{1,2}\right)$, and postoesophageal areas $(\mathrm{PoDM})$ of the synganglion (Figs. 3A,C, 4A). One additional pair of small dorsal neurons was found in the pedal lobe $4\left(\mathrm{Pd}_{4} \mathrm{DM}_{1,2}\right)$ of I. scapularis (Fig. 4A) that was not observed in $R$. appendiculatus. On the ventral side, staining was found in the protocerebrum (PcVM), pedal lobes 2-4 $\left(\mathrm{Pd}_{2-4} \mathrm{VM}\right)$, and opistosomal lobe $(\mathrm{OsVM}$, OsIN $1-5)$, which is similar to the staining patterns observed in $R$. appendiculatus. Some small ventral neurons were uniquely stained in I. scapularis, particularly in the stomodeal lobe $\left(\mathrm{StVM}_{1-3}\right)$, pedal lobe 1 $\left(\mathrm{Pd}_{1} \mathrm{VL}_{1,2}\right)$, and lateral segmental neurons in pedal lobes $1-4\left(\mathrm{Pd}_{1-4} \mathrm{VL}\right.$; Figs. 3D, $\left.4 \mathrm{C}\right)$; these were not found in $R$. appendiculatus.

Antisera against SIFamide peptide showed immunoreactivity in various neurons on the dorsal and ventral sides of the synganglion. Two pairs of small interneurons were found in the central region of the dorsal protocerebrum $\left(\mathrm{PcIN}_{1,2} ;\right.$ Figs. 3B, 4B). A single pair of giant neurons (PcSG) showing coexpression of SIFamide and MIP was located in the posterior part of the protocerebrum (Figs. 3A-C, 4A,B). We also detected four SIFamideimmunoreactive medial neurons on the ventral side of the protocerebrum $\left(\mathrm{PcVM}_{1-4}\right)$. Those neurons projected a loop of paired axons posteriorly that arborized in the pedal lobe regions within the synganglion (Figs. 3E,F, 4D). The cheliceral lobes included a pair of SIFamideimmunoreactive neurons on the dorsal side $(\mathrm{ChD})$. The dorsal pedal region contained a pair of small lateral neurons $\left(\mathrm{Pd}_{1} \mathrm{DL}_{1,2}, \mathrm{Pd}_{2} \mathrm{DL}_{1,2}\right)$ and medial neuronal cells $\left(\mathrm{Pd}_{3} \mathrm{DM}_{1,2}\right)$, which showed coexpression with SIFamide and MIP (Figs. 3A-C, 4A,B). Two small medial neurons (PoDM) and two small interneurons (OsIN) were detected in the posterior synganglion (Fig. 4B), whereas a pair of small medial neurons was found in each pedal lobe $3\left(\mathrm{Pd}_{3} \mathrm{VM}\right.$; Fig. 4D).

In situ hybridization confirmed the immunohistochemistry in a subset of neuronal cell bodies. In the in situ hybridization of mip, strong reactions were detected in protocerebrum cells PcIN and PcSG (Fig. 5A,B). We also recognized weak reactions in small neurons in cheliceral lobes and pedal lobes $2-4\left(\mathrm{ChD}_{1-3}, \mathrm{Pd}_{2} \mathrm{DL}, \mathrm{Pd}_{2-4} \mathrm{VM}\right.$; Fig. 5A,B). In situ hybridization of sifamid revealed the reactivity in cheliceral neurons $(\mathrm{ChD})$, protocerebrum $\left(\mathrm{PcIN}_{1,2}, \mathrm{PcSG}\right)$, and pedal lobes 2-3 $\left(\mathrm{Pd}_{1} \mathrm{DL}_{1}, \mathrm{Pd}_{2} \mathrm{DL}_{1,2}, \mathrm{Pd}_{3} \mathrm{DM}_{1,2} ;\right.$ Fig. 5C,D).

\section{MIP and SIFamide in innervation of the salivary glands}

By using MIP and SIFamide antibodies, we identified a pair of neurons in the synganglion that innervated the salivary glands of I. scapularis. Double staining with both antibodies revealed coexpression of MIP and SIFamide in a pair of giant neurons (PcSG) in the protocerebral lobe, each projecting a single thick axonal process without varicosities in a loop, which is often not visible (Figs. 3A-C, 4A,B). The axonal projection exited the synganglion through the palpal nerve and salivary nerve I (Fig. 4A,B), ran along salivary duct surface, and produced multiple branches and terminated in salivary acini types II and III, but not in type I (Figs. 6A-L, 7A-C). Each axonal branch entered individual acini through the neck region and arborized into four or five and three or four axon terminals containing varicosities on types II and III acini, respectively. These axon terminals were likely in contact with the luminal surface of the acini (Figs. 6A-L, 7B,C). 


\section{MIP and SIFamide genes}

The coding sequence of MIP is $496 \mathrm{bp}$ and is transcribed from a gene composed of four exons interrupted by three large introns. The open reading frame (ORF) encodes 132 amino acid residues of the MIP prepropeptide and contains three putative MIP-like sequences (Fig. 1B). Three putative MIP-related peptides were identified: MIP1 (-DWNALSGMWamide), which had an unknown N-terminus; MIP2 (ASDWNRLSGMWamide) and MIP3 (WNDLSGYW), with unknown N-terminus and containing canonical Gly (G) for possible amidation but lacking cleavage amino acid(s) at the C-terminus (Fig. 1B). So far, only the presence of MIP2 has been confirmed in the CNS and salivary gland extracts by MALDITOF analysis.

A search for the SIFamide motif in the $I$. scapularis sequence database identified six EST sequences (GenBank Accession Nos. EW859993, EW859992, EL516526, EW878394, EL516675, and EL515586) and revealed a 515-bp transcript containing an ORF for 74 amino acid residues of the SIFamide prepropeptide. By comparison with the genome sequence, we identified four exons interrupted by three introns $(677,8,104$, and 3,134 bp; Fig. 2B). The mature peptide AYRKPPFNGSIFamide, which was identified in the MALDITOF analysis, was located immediately after the predicted signal peptide and was followed by canonical amidation and cleavage signals (GKR). Notably, there were polymorphisms observed upon comparison among multiple EST clones and genome sequences; however, the sequence that we present is based on the genome sequence (Fig. 2B).

\section{Mass spectra analyses of MIP and SIFamide peptides}

We predicted that neuropeptides produced by central neurons and delivered via axonal projections to salivary ducts and acini could be detected in MALDI peaks that were present in both the extracts of the synganglia and the salivary glands. Indeed, two MALDI peaks were present in both extracts: $[\mathrm{M}+\mathrm{H}]^{+} 1,322$ and $1,396 \mathrm{Da}$ (Fig. 8A-D). Tandem mass spectrometry of these peaks provided partial sequences and amino acid compositions, but accurate determination of the whole sequence was not possible. Combining this information with data from the $I$. scapularis sequence database yielded sequences corresponding to MIP2 (ASDWNRLSGMWamide $[\mathrm{M}+\mathrm{H}]^{+}: 1,321.6106 \mathrm{Da}$ ) and SIFamide (AYRKPPFNGSIFamide $[\mathrm{M}+\mathrm{H}]^{+}: 1,395.7532 \mathrm{Da}$ ) as the best matches. Ultimately, MIP2 and SIFamide were chemically synthesized and run on MALDI. We found that the tandem mass spectrometry profiles of these synthetic peptides were nearly identical to patterns found for the 1,322- and the 1,396-Da peaks of the synganglia extract (Fig. 9A-D). Both the extracts of the synganglia and the salivary glands contained another peak (1,394 Da), which almost overlapped with SIFamide (1,396 Da), but its identity is still unknown (Fig. 8B,D).

\section{DISCUSSION}

Various components of tick salivary secretions have been extensively studied. These secretions contain multiple cement proteins important for attachment and feeding of ticks as well as anticoagulants and immunosuppressive polypeptides that modulate the host's immune responses (Bishop et al., 2002; Trimnell et al., 2005). Feeding ticks may efficiently transfer various pathogens, causing serious diseases to their host. Therefore, disruption of tick salivary function has been attempted to prevent infections with the tick-borne pathogens by vaccination of mammalian hosts with selected salivary proteins (Wikel, 1996). However, the mechanism underlying neural and hormonal control of salivary secretion is poorly understood. Several studies have focused on identification of aminergic regulatory pathways controlling the secretory activity of tick salivary glands (Kaufman, 1978; Sauer et al., 1995, 2000). Dopamine has been found to activate salivary secretion through the D1-type (excitatory) receptor, which is likely a G-protein-coupled receptor (GPCR; Sauer et al., 
1994; Schmidt et al., 1981). The downstream signaling pathway involves the G-protein alpha subunit S, cyclic AMP, and protein kinases for the excretion of water. A separate calcium-dependent pathway is activated for the production of prostaglandin E2 (PGE2; Maritz-Olivier et al., 2005). Additional biogenic amines, such as adrenaline, pilocarpine (muscarinic acetylcholine agonist), and high concentrations of octopamine, also activate salivary secretion (Kaufman, 1978; Kaufman and Wong, 1983). Additionally, a single report suggests that an unidentified peptide or protein from brain extracts elicits formation of inositol phosphates in salivary glands (McSwain et al., 1989).

Our recent studies indicate that complex mechanisms control the functions of the salivary glands, including peptidergic regulatory pathways. We have previously described MIP-like immunoreactivity in coupled giant neurons and their projections to salivary glands in the tick $R$. appendiculatus (Šimo et al., 2009). In this report, we identified two neuropeptides (MIP and SIFamide) and corresponding genes expressed in these neurons in the blacklegged tick, I. scapularis. Close association of MIP- and SIFamide-immunoreactive axon termini with specific cells in salivary acini indicates the importance of peptidergic regulation of salivary gland activity.

MIPs (also called allatostatins $B$ ) have been identified in a number of insect species. These short neuropeptides are generally characterized by two conserved tryptophan residues contained within a W(6x)Wamide motif (Fig. 1A). In D. melanogaster and Tribolium castaneum, the mip gene encodes five or six homologous peptides, whereas multiple copies of seven closely related MIPs are expressed in Bombyx mori and Manduca sexta (Li et al., 2008). Recently, MIPs have been found in a crustacean by using MALDI analysis (Schmidt et al., 2008), indicating that this conserved class of neuropeptides may exist in most arthropods. The first MIP was originally identified as a potent inhibitor in the locust heartbeat bioassay (Schoofs et al., 1991). Closely related orthologs have since been identified in other species based on their inhibitory effects in various in vitro bioassays, such as the inhibition of juvenile hormone production in crickets (Lorenz et al., 1995a,b), the suppression of ecdysone secretion from prothoracic glands in the silk moth (Hua et al., 1999), and the inhibition of spontaneous peristaltic contractions of the adult $M$. sexta hindgut (Blackburn et al., 2001). Recently, it was proposed to act as a cotransmitter with other neuropeptides in the regulation of ecdysis behavior in M. sexta and D. melanogaster (Davis et al., 2003; Kim et al., 2006).

SIFamides have been found to be identical neuropeptides in different species of crustaceans and insects, except for the variation of a single amino acid at the N-terminus (Fig. 2A; Hauser et al., 2006; Yasuda et al., 2004). The anatomical structure of SIFamideimmunopositive neurons indicates that this peptide acts as a neuromodulator within the CNS to modulate the olfactory system in the crayfish Procambarus clarkii (Yasuda-Kamatani and Yasuda, 2006; Yasuda et al., 2004). Endocrine cells in the anterior midgut of Cancer sp. are a rich source of SIFamide (Christie et al., 2007). One possible role of this midgut peptide has been examined in the lobster Homarus americanus. Injection of SIFamide elicited myostimulatory action on the pyloric valve, which regulates the flow of food particles from the foregut to the midgut (Christie et al., 2006). SIFamide expression is limited to only four brain interneurons in D. melanogaster and B. mori (Roller et al., 2009; Terhzaz et al., 2007). Targeted ablation of these neurons or RNA interference have shown that SIFamide controls male and female sexual behavior in D. melanogaster (Terhzaz et al., 2007). The gene encoding SIFamide in ticks has been recently described (Christie, 2008; Verleyen et al., 2008), and we provide further details of the gene annotation in this study (Fig. 2B).

MIP and SIFamide immunoreactivities were observed in many regions of the I. scapularis synganglion, but a clear colocalization of these peptides was found only in PcSG and 
$\mathrm{Pd}_{3} \mathrm{DM}_{1,2}$ neurons. It is noteworthy that the MIP-IR in the PcSG cell bodies was stronger than that in axon and axon termini in the acini, whereas SIFamide-IR is weaker in cell bodies and stronger in the axonal projections, although accurate quantification was not possible (data not shown). In situ hybridization for the mip also produced more robust and stronger signals in the PcSG neurons than that for sifamide. PcSG neurons have been identified as a source of innervation of acini II and III in many ixodid ticks, and the innervation patterns of the entire salivary glands in I. scapularis and $R$. appendiculatus are very similar (Šimo et al., 2009). However, it is noteworthy that axon termini on individual acini of Ixodes spp. (I. scapularis and I. ricinus) are unique compared with those observed in other tick species (D. reticulatus, $R$. appendiculatus, and A. variegatum; Šimo and Park, unpublished). In Ixodes spp., axon terminals in acini II and III showed the characteristic four or five and three or four branches, respectively, whereas two short branches were commonly observed in other tick species.

Observations of salivary glands using confocal microscopy provided a counterpoint to classical studies that used light microscopy and transmission electron microscopy (Balashov et al., 1983; Coons and Alberti, 1999). Patterns and locations of different nuclei visualized by DAPI were highly reproducible in 3D reconstructions of confocal images (Fig. 6A-L). In acini II, nuclei could be categorized into four groups: small nuclei located on the neck of an acinus, small nuclei located between large nuclei dispersed over the surface of an acinus, the major category of large nuclei in granular cells located basal region of acini, and large nuclei clustered in the apical region of acini. In acini III, at least five types of nuclei were observed: small nuclei located on the neck, large nuclei clustered in the apical region of the acinus, scattered small nuclei in between the large nuclei in the apical region, three or four large nuclei located in the basal part of the acinus, and two large elliptical nuclei neighboring the basal large nuclei. The most probable targets of innervation are four or five basal granular cells in the acini II and three or four basally located cells with large nuclei in acini III. According to the previous anatomical descriptions of tick salivary glands in various species (Binnington, 1978), the basal three or four cells in the acini III might be $d$-cells, whereas the granular cells in acini II could not be accurately compared with the earlier studies.

The large MALDI peak at $[\mathrm{M}+\mathrm{H}]$ 1,396 that was characterized as a SIFamide peptide in this study seems to also occur in A. americanum, although we do not know whether this peak represents an identical SIFamide (Šimo and Park, unpublished data). A previous study characterizing periviscerokinin peptides (Neupert et al., 2005) also reported a 1,396-Da peak in the MALDI analysis of single cheliceral neurons in I. ricinus, but successful fragmentation of this peak was not possible. Considering that SIFamide is a highly conserved peptide, the 1,396-Da peaks found in other tick species might represent the SIFamide that we characterized in this study.

Our data provide evidence that projections of PcSG neurons innervating salivary glands contain MIP and SIFamide. However, the functions of these two neuropeptides in the control of the salivary glands have not been elucidated. The generalized functions of these two peptides, MIP and SIFamide, might be antagonistic, with inhibitory function of MIP and stimulatory action of SIFamide. The identification of these neuropeptides and the genes encoding them and the description of their expression patterns in the synganglion and the specific innervation of acini reported in this study will lead to further investigations of salivary gland regulation.

\section{Supplementary Material}

Refer to Web version on PubMed Central for supplementary material. 


\section{Acknowledgments}

We thank Dr. John Tomich and Dr. Takeo Iwamoto in the Biotechnology/Proteomics Core Lab at Kansas State University for assistance with the MALDI analysis. We are also grateful to Drs. Akira Mizoguchi and Jan Veenstra for providing the MIP and SIFamide antibodies. This is Contribution Number 09-281-J from the Kansas Agricultural Experimental Station. The sequences for mip and sifamide genes were deposited in GenBank with accession numbers GQ214555 and GQ214556, respectively.

Grant sponsor: National Institutes of Health; Grant number: R21 AI081136-01; Grant number: NIH-COBRE-P20RR017686.

\section{Abbreviations}

$\begin{array}{ll}\text { ChD } & \text { cheliceral dorsal neuron } \\ \text { OsIN } & \text { opistosomal interneuron } \\ \text { OsVM } & \text { opistosomal ventromedial neuron } \\ \text { PaN } & \text { palpal nerve } \\ \text { PaD } & \text { palpal dorsal neuron } \\ \text { PcAM } & \text { protocerebral anteromedial neuron } \\ \text { PcIN } & \text { protocerebral interneuron } \\ \text { PcSG } & \text { protocerebral neurons inervating salivary glands } \\ \text { PcVM } & \text { protocerebral ventromedial neuron } \\ \text { PdDL } & \text { pedal dorsolateral neuron } \\ \text { PdDM } & \text { pedal dorsomedial neuron } \\ \text { PDF } & \text { pigment dispersing factor } \\ \text { PdVM } & \text { pedal ventromedial neuron } \\ \text { PdVL } & \text { pedal ventrolateral neuron } \\ \text { PoDM } & \text { postoesophageal dorsal neuron } \\ \text { SgN1 } & \text { salivary nerve 1 } \\ \text { StVM } & \text { stomodeal ventromedial neuron }\end{array}$

\section{LITERATURE CITED}

Balashov, IUS.; Raikhel, AS.; Hoogstraal, H. An atlas of ixodid tick ultrastructure. Entomological Society of America; Washington, DC: 1983.

Binnington KC. Sequential changes in salivary gland structure during attachment and feeding of the cattle tick, Boophilus microplus. Int J Parasitol. 1978; 8:97-115. [PubMed: 681074]

Bishop R, Lambson B, Wells C, Pandit P, Osaso J, Nkonge C, Morzaria S, Musoke A, Nene V. A cement protein of the tick Rhipicephalus appendiculatus, located in the secretory e cell granules of the type III salivary gland acini, induces strong antibody responses in cattle. Int J Parasitol. 2002; 32:833-842. [PubMed: 12062554]

Blackburn MB, Jaffe H, Kochansky J, Raina AK. Identification of four additional myoinhibitory peptides (MIPs) from the ventral nerve cord of Manduca sexta. Arch Insect Biochem Physiol. 2001; 48:121-128. [PubMed: 11673841]

Christie AE. Neuropeptide discovery in Ixodoidea: an in silico investigation using publicly accessible expressed sequence tags. Gen Comp Endocrinol. 2008; 157:174-185. [PubMed: 18495123]

Christie AE, Stemmler EA, Peguero B, Messinger DI, Provencher HL, Scheerlinck P, Hsu YW, Guiney ME, de la Iglesia HO, Dickinson PS. Identification, physiological actions, and distribution 
of VYRKPPFNGSIFamide (Val1)-SIFamide in the stomatogastric nervous system of the American lobster Homarus americanus. J Comp Neurol. 2006; 496:406-421. [PubMed: 16566002]

Christie AE, Kutz-Naber KK, Stemmler EA, Klein A, Messinger DI, Goiney CC, Conterato AJ, Bruns EA, Hsu YW, Li L, Dickinson PS. Midgut epithelial endocrine cells are a rich source of the neuropeptides APSGFLGMRamide (Cancer borealis tachykinin-related peptide Ia) and GYRKPPFNGSIFamide (Gly1-SIFamide) in the crabs Cancer borealis, Cancer magister and Cancer productus. J Exp Biol. 2007; 210:699-714. [PubMed: 17267655]

Coons, LB.; Alberti, G. The acari-ticks. In: Harrison, FW.; Foelix, R., editors. Microscopic anatomy of invertebrates. Vol. vol 8B. Wiley-Liss; Chelicerate Arthropoda. New York: 1999. p. 267-514.

Coons LB, Roshdy MA. Fine structure of the salivary glands of unfed male Dermacentor variabilis (Say) (Ixodoidea: Ixodidae). J Parasitol. 1973; 59:900-912. [PubMed: 4744522]

Davis HH, Dotson EM, Oliver JH Jr. Localization of insulin-like immunoreactivity in the synganglion of nymphal and adult Dermacentor variabilis (Acari: Ixodidae). Exp Appl Acarol. 1994; 18:111122. [PubMed: 7628242]

Davis NT, Blackburn MB, Golubeva EG, Hildebrand JG. Localization of myoinhibitory peptide immunoreactivity in Manduca sexta and Bombyx mori, with indications that the peptide has a role in molting and ecdysis. J Exp Biol. 2003; 206:1449-1460. [PubMed: 12654884]

Emanuelsson O, Brunak S, von Heijne G, Nielsen H. Locating proteins in the cell using TargetP SignalP and related tools. Nat Protoc. 2007; 2:953-971. [PubMed: 17446895]

Hauser F, Williamson M, Cazzamali G, Grimmelikhuijzen CJ. Identifying neuropeptide and protein hormone receptors in Drosophila melanogaster by exploiting genomic data. Briefings Function Genom Proteom. 2006; 4:321-330.

Holmes SP, He H, Chen AC, lvie GW, Pietrantonio PV. Cloning and transcriptional expression of a leucokinin-like peptide receptor from the southern cattle tick, Boophilus microplus (Acari: Ixodidae). Insect Mol Biol. 2000; 9:457-465. [PubMed: 11029664]

Holmes SP, Barhoumi R, Nachman RJ, Pietrantonio PV. Functional analysis of a G protein-coupled receptor from the southern cattle tick Boophilus microplus (Acari: Ixodidae) identifies it as the first arthropod myokinin receptor. Insect Mol Biol. 2003; 12:27-38. [PubMed: 12542633]

Hua YJ, Tanaka Y, Nakamura K, Sakakibara M, Nagata S, Kataoka H. Identification of a prothoracicostatic peptide in the larval brain of the silkworm, Bombyx mori. J Biol Chem. 1999; 274:31169-31173. [PubMed: 10531308]

Kaufman WR. Actions of some transmitters and their antagonists on salivary secretion in a tick. Am J Physiol. 1978; 235:R76-R81. [PubMed: 677342]

Kaufman WR, Wong DL. Evidence for multiple receptors mediating fluid secretion in salivary glands of ticks. Eur J Pharmacol. 1983; 87:43-52. [PubMed: 6188618]

Kim YJ, Žitňan D, Cho KH, Schooley DA, Mizoguchi A, Adams ME. Central peptidergic ensembles associated with organization of an innate behavior. Proc Natl Acad Sci U S A. 2006; 103:1421114216. [PubMed: 16968777]

Krolak JM, Ownby CL, Sauer JR. Alveolar structure of salivary glands of the lone star tick, Amblyomma americanum (L.): unfed females. J Parasitol. 1982; 68:61-82. [PubMed: 7200514]

Li B, Predel R, Neupert S, Hauser F, Tanaka Y, Cazzamali G, Williamson M, Arakane Y, Verleyen P, Schoofs L, Schachtner J, Grimmelikhuijzen CJ, Park Y. Genomics, transcriptomics, and peptidomics of neuropeptides and protein hormones in the red flour beetle Tribolium castaneum. Genome Res. 2008; 18:113-122. [PubMed: 18025266]

Lorenz MW, Kellner R, Hoffmann KH. A family of neuropeptides that inhibit juvenile hormone biosynthesis in the cricket, Gryllus bimaculatus. J Biol Chem. 1995a; 270:21103-21108. [PubMed: 7673141]

Lorenz MW, Kellner R, Hoffmann KH. Identification of two allatostatins from the cricket, Gryllus bimaculatus de Geer (Ensifera, Gryllidae): additional members of a family of neuropeptides inhibiting juvenile hormone biosynthesis. Regul Pept. 1995b; 57:227-236. [PubMed: 7480872]

Maritz-Olivier C, Louw AI, Neitz AW. Similar mechanisms regulate protein exocytosis from the salivary glands of ixodid and argasid ticks. J Insect Physiol. 2005; 51:1390-1396. [PubMed: 16226274] 
McSwain JL, Tucker JS, Essenberg RC, Sauer JR. Brain factor induced formation of inositol phosphates in tick salivary gland. Insect Biochem. 1989; 19:343-350.

Neupert S, Predel R, Russell WK, Davies R, Pietrantonio PV, Nachman RJ. Identification of tick periviscerokinin, the first neurohormone of Ixodidae: single cell analysis by means of MALDITOF/TOF mass spectrometry. Biochem Biophys Res Commun. 2005; 338:1860-1864. [PubMed: 16289040]

Roller L, Yamanaka N, Watanabe K, Daubnerová I, Žitňan D, Kataoka H, Tanaka Y. The unique evolution of neuropeptide genes in the silkworm Bombyx mori. Insect Biochem Mol Biol. 2009; 38:1147-1157. [PubMed: 19280707]

Sauer JR, McSwain JL, Essenberg RC. Cell membrane receptors and regulation of cell function in ticks and blood-sucking insects. Int J Parasitol. 1994; 24:33-52. [PubMed: 8021107]

Sauer JR, McSwain JL, Bowman AS, Essenberg RC. Tick salivary gland physiology. Annu Rev Entomol. 1995; 40:245-267. [PubMed: 7810988]

Sauer JR, Essenberg RC, Bowman AS. Salivary glands in ixodid ticks: control and mechanism of secretion. J Insect Physiol. 2000; 46:1069-1078. [PubMed: 10817833]

Schmidt JJ, McIlwain S, Page D, Christie AE, Li L. Combining MALDI-FTMS and bioinformatics for rapid peptidomic comparisons. J Proteome Res. 2008; 7:887-896. [PubMed: 18205299]

Schmidt SP, Essenberg RC, Sauer JR. Evidence for a D1 dopamine receptor in the salivary glands of Amblyomma americanum(L.). J Cyclic Nucleotide Res. 1981; 7:375-384. [PubMed: 7346526]

Schoofs L, Holman GM, Hayes TK, Nachman RJ, De Loof A. Isolation, identification and synthesis of locustamyoinhibiting peptide (LOM-MIP), a novel biologically active neuropeptide from Locusta migratoria. Regul Pept. 1991; 36:111-119. [PubMed: 1796179]

Šimo L, Slovák M, Park Y, Žitňan D. Identification of a complex peptidergic neuroendocrine network in the hard tick, Rhipicephalus appendiculatus. Cell Tissue Res. 2009; 335:639-655. [PubMed: 19082627]

Sonenshine, DE. Biology of ticks. Oxford University Press; New York: 1993.

Taneja-Bageshwar S, Strey A, Zubrzak P, Pietrantonio PV, Nachman RJ. Comparative structureactivity analysis of insect kinin core analogs on recombinant kinin receptors from southern cattle tick Boophiyylus microplus (Acari: Ixodidae) and mosquito Aedes aegypti (Diptera: Culicidae). Arch Insect Biochem Physiol. 2006; 62:128-140. [PubMed: 16783824]

Terhzaz S, Rosay P, Goodwin SF, Veenstra JA. The neuropeptide SIFamide modulates sexual behavior in Drosophila. Biochem Biophys Res Commun. 2007; 352:305-310. [PubMed: 17126293]

Trimnell AR, Davies GM, Lissina O, Hails RS, Nuttall PA. A cross-reactive tick cement antigen is a candidate broad-spectrum tick vaccine. Vaccine. 2005; 23:4329-4341. [PubMed: 15913855]

Verleyen P, Huybrechts J, Schoofs L. SIFamide illustrates the rapid evolution in Arthropod neuropeptide research. Gen Comp Endocrinol. 2008 (in press).

Wikel SK. Host immunity to ticks. Annu Rev Entomol. 1996; 41:1-22. [PubMed: 8546443]

Yasuda A, Yasuda-Kamatani Y, Nozaki M, Nakajima T. Identification of GYRKPPFNGSIFamide (crustacean-SIFamide) in the crayfish Procambarus clarkii by topological mass spectrometry analysis. Gen Comp Endocrinol. 2004; 135:391-400. [PubMed: 14723891]

Yasuda-Kamatani Y, Yasuda A. Characteristic expression patterns of allatostatin-like peptide, FMRFamide-related peptide, orcokinin, tachykinin-related peptide, and SIFamide in the olfactory system of crayfish Procambarus clarkii. J Comp Neurol. 2006; 496:135-147. [PubMed: 16528723]

Zhu XX, Oliver JH Jr. Immunocytochemical localization of an insulin-like substance in the synganglion of the tick Ornithodoros parkeri (Acari: Argasidae). Exp Appl Acarol. 1991; 13:153159. [PubMed: 1786746]

Zhu XX, Zhang WY, Oliver JH Jr. Immunocytochemical mapping of FMRFamide-like peptides in the argasid tick Ornithodoros parkeri and the ixodid tick Dermacentor variabilis. Exp Appl Acarol. 1995; 19:1-9. [PubMed: 7621708]

Žitňanová I, Adams ME, Žitňan D. Dual ecdysteroid action on the epitracheal glands and central nervous system preceding ecdysis of Manduca sexta. J Exp Biol. 2001; 204:3483-3495. [PubMed: 11707498] 
A

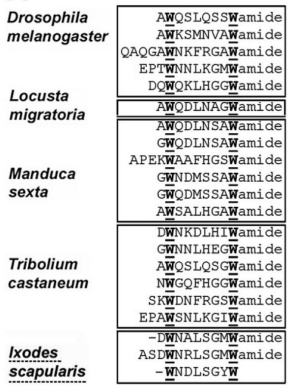

B

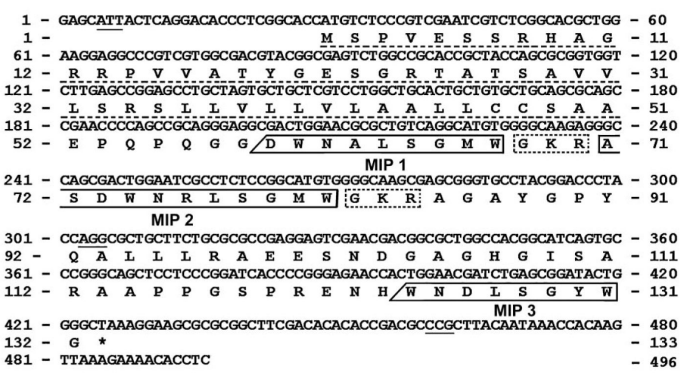

Figure 1.

Highly conserved MIPs shown by alignment of putative mature peptide sequences from various species: insect and arachnid (Ixodes scapularis; $\mathbf{A}$ ). Strictly conserved $\mathrm{W}$ are underlined in the $\mathrm{W}(6 \mathrm{x})$ Wamide motif. Nucleotide sequence and conceptual translations of the cDNA encoding MIPs in I. scapularis (B). The three nucleotide sequences at the end of each exon are underscored. The putative mature MIPs are boxed (solid line), while uncertain $\mathrm{N}$-terminal ends are marked with slashed boxes. Canonical dibasic cleavage and amidation signals GKR are boxed with dotted lines. The predicted signal peptide is underscored with a dotted line. The translation stop codon is marked by an asterisk. 
A

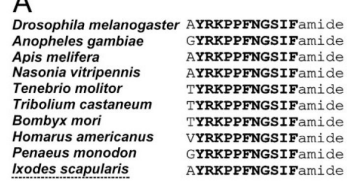

B

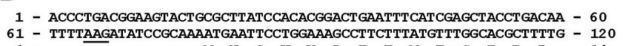

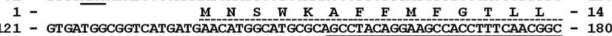

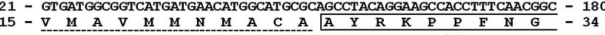

181 - AGCATATTCGGCAAGAGGTCCAGGGCAGACCTGAACAACGCAGATGTGAAARACGCAATG - 240

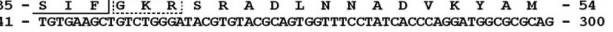

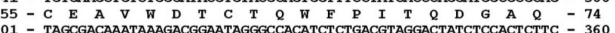

- CCTGACTCCCAGTAGACTCCCTGGAGACGATCGCTCCGTCGCCTCGT GAACCTGCACAGC - 420

- TCTTCTTGAGAAGCAAGACTTCTCCCTGGAGGCACCTCCATGTCAACAAAACTAGTTAGA - 45

Figure 2.

Alignment of SIFamide peptides from various species: insect, crustacean (Homarus americanus), and arachnid (Ixodes scapularis; $\mathbf{A}$ ). Strictly conserved sequences are in boldface, except for the one variable amino acid in the N-termini. Nucleotide sequence and conceptual translations of the cDNA encoding the SIFamide in I. scapularis $(\mathbf{B})$. The three nucleotide sequences at the end of each exon are underscored. The putative mature peptides for the SIFamide sequence are boxed (solid line). The canonical dibasic cleavage and the amidation signal GKR are boxed with a dotted line. The signal peptide is underscored with a dotted line. The stop codon is marked by an asterisk. 

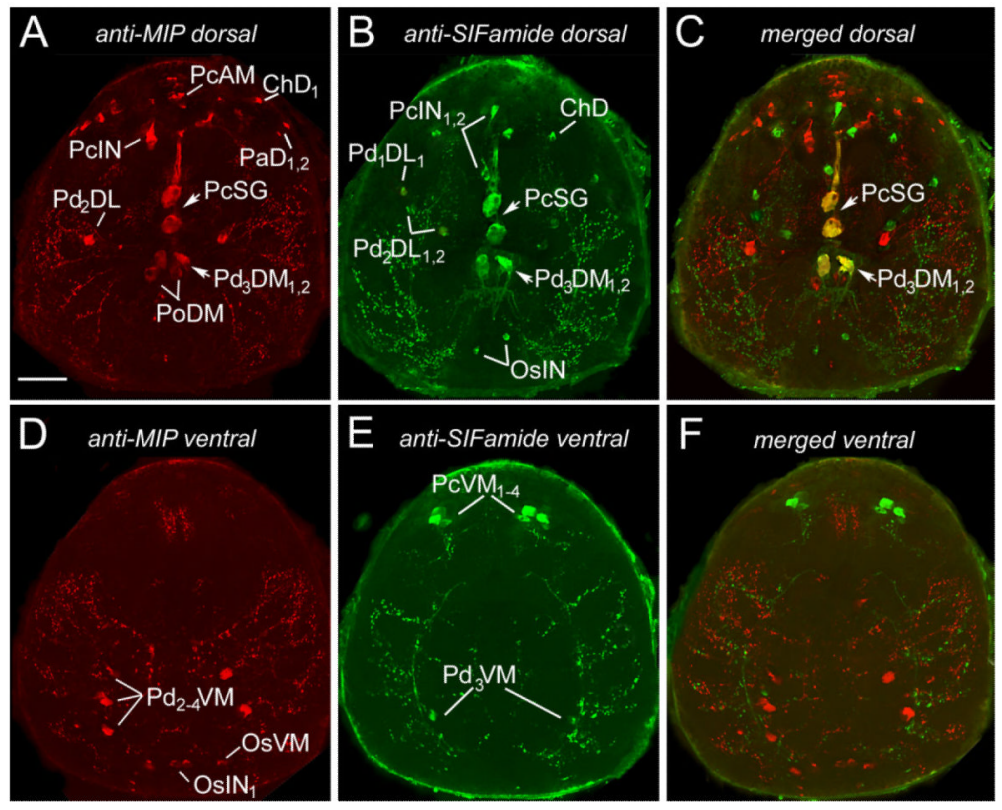

\section{Figure 3.}

Immunohistochemistry showing double staining of neurons producing MIP and SIFamide and their projections in the tick synganglion (see nomenclature of peptidergic neurons and list of Abbreviations). Double staining with antibodies to MIP (red; A, dorsal; D, ventral) and to SIFamide (green; B, dorsal; $\mathbf{E}$, ventral) revealed different sets of neurons in both dorsal and ventral areas of the synganglion. Coexpression of MIP and SIFamide, shown as yellow in the merged image $(\mathbf{C})$, was detected in medial pedal neurons $\left(\mathrm{Pd}_{3} \mathrm{DM}_{1,2}\right)$ and giant protocerebral neurons (PcSG). Note that coexpression on the ventral side of the synganglion was not detected $(\mathbf{F})$. This figure is repeated as Supporting Information Figure 1, with the red-green double label replaced by magenta-green. Scale bar $=50 \mu \mathrm{m}$. 
A

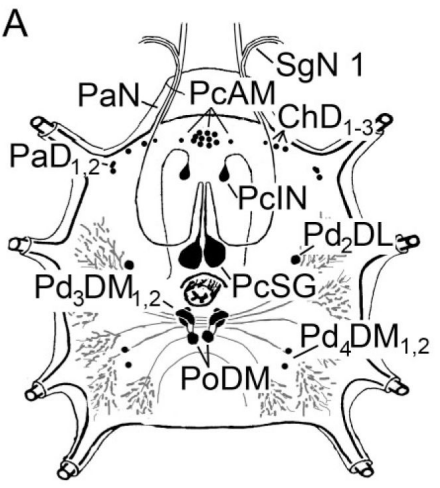

C

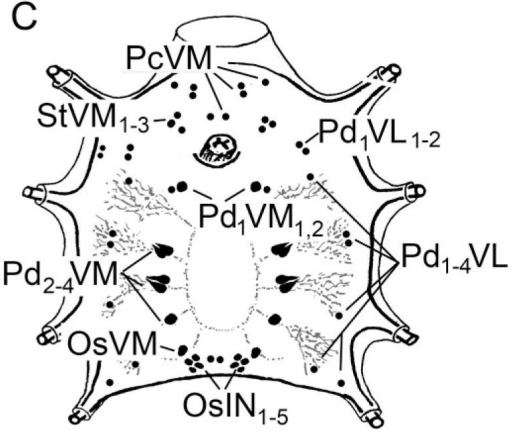

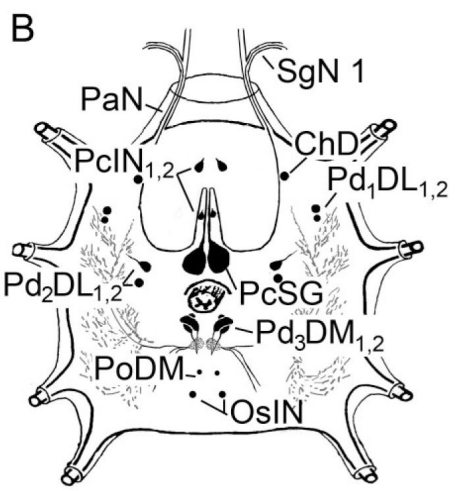

D

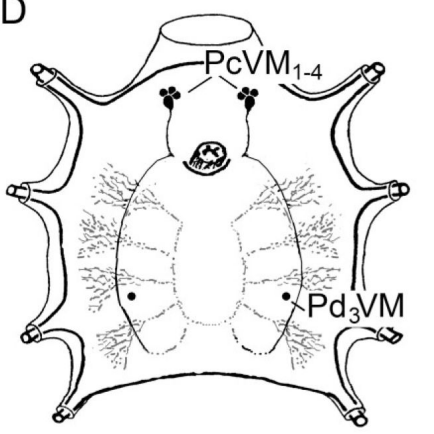

Figure 4.

Schematic diagram showing all peptidergic neurons described in this study. MIP-IR (A, dorsal; $\mathbf{C}$, ventral) and SIFamide-IR (B, dorsal; $\mathbf{D}$, ventral) in cells and projections in a synganglion for both dorsal and ventral views. See nomenclature of peptidergic neurons and list of Abbreviations. Scale bar $=50 \mu \mathrm{m}$. 

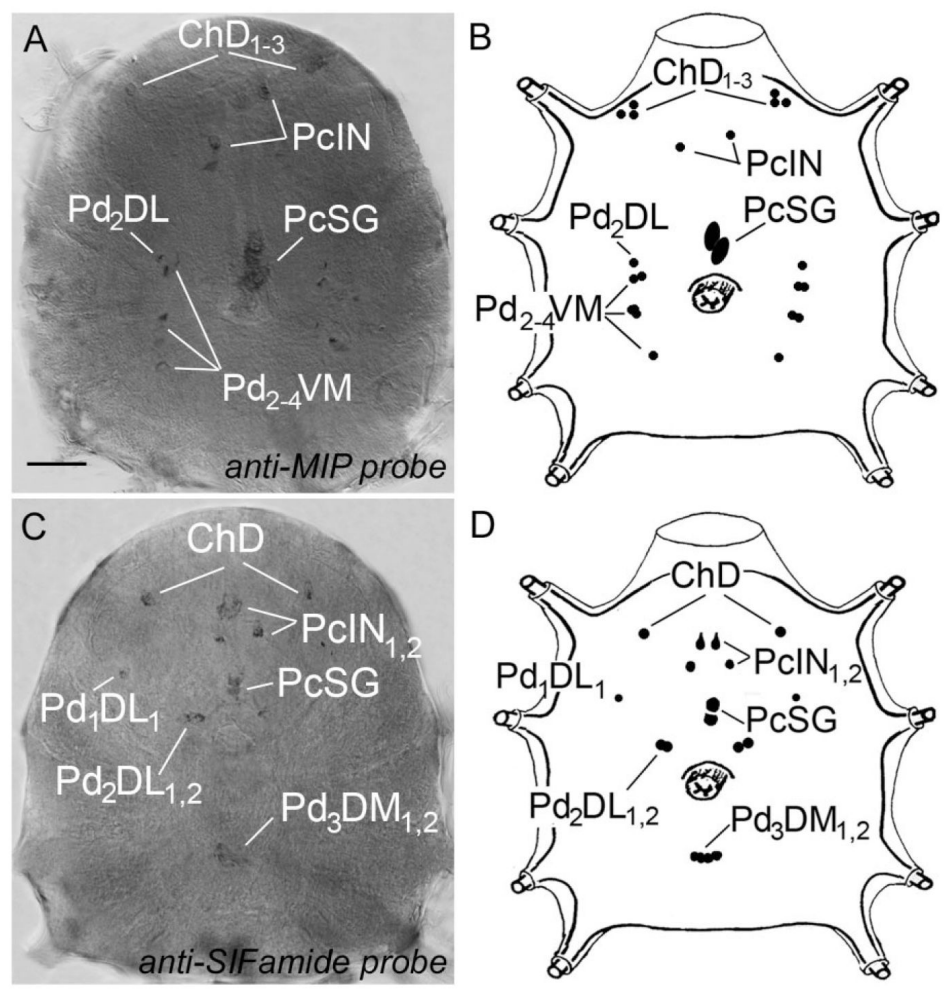

Figure 5.

In situ hybridization staining and schematic drawing in synganglion of MIP $(\mathbf{A}, \mathbf{B})$ and SIFamide (C,D) with antisense probe for representative gene. Note that reaction in PcSG neurons is stronger in the case of MIP (A) than in the case of SIFamide (C). See nomenclature of peptidergic neurons and list of Abbreviations. Scale bar $=50 \mu \mathrm{m}$. 


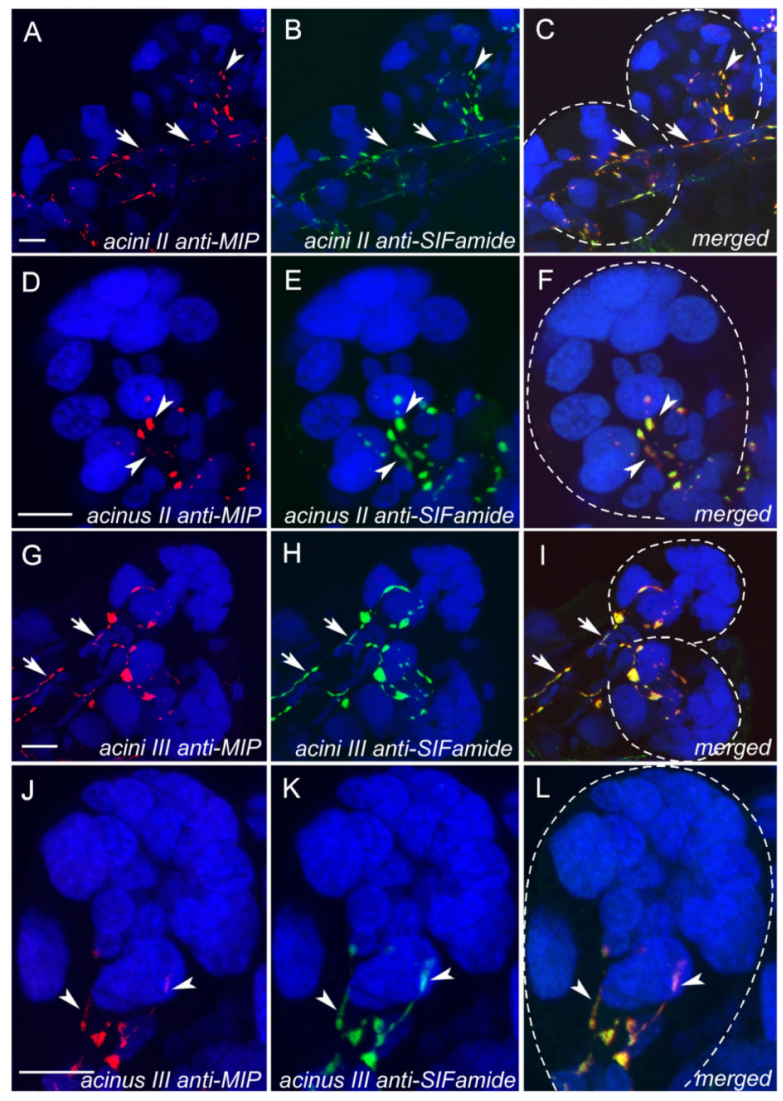

Figure 6.

Colocalization of MIP-IR (red in the first column; A,D,G,J) and SIFamide-IR in projections (green in the second column; B,E,H,K), and merged images (third column; C,F,I,L) of the salivary glands. Blue is nuclei staining for DAPI. Two different magnifications for acini II $(\mathrm{A}-\mathrm{F})$ and acini III $(\mathrm{G}-\mathrm{L})$ are shown. D-F and $\mathrm{J}-\mathrm{L}$ are higher magnifications. Arrows indicate axons running along the salivary duct, and arrowheads indicate the varicosities of the axon terminal branches in acini. This figure is repeated as Supporting Information Figure 2 , with the red-green double label replaced by magenta-green. Scale bars $=10 \mu \mathrm{m}$ in A (applies to A-C); $10 \mu \mathrm{m}$ in D (applies to D-F); $10 \mu \mathrm{m}$ in $\mathrm{G}$ (applies to G-I); $10 \mu \mathrm{m}$ in J (applies to $\mathrm{J}-\mathrm{L}$ ). 

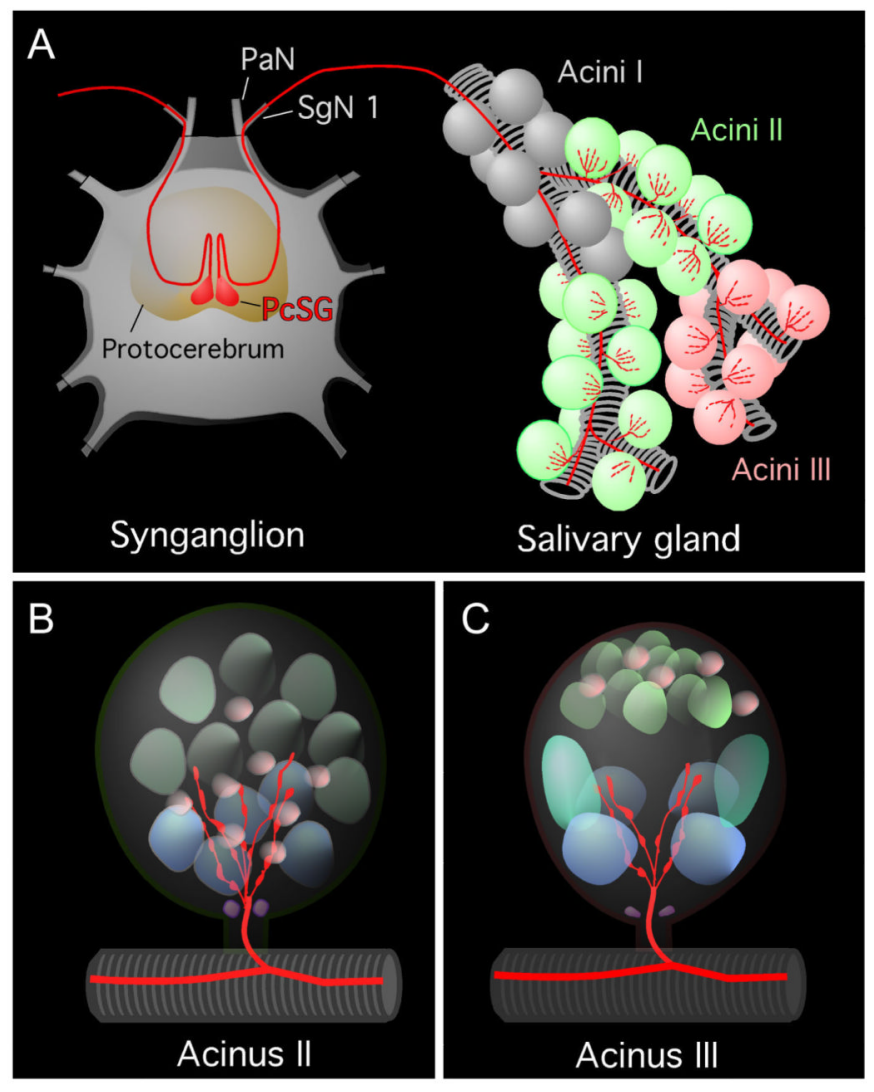

Figure 7.

A: Simplified schematic diagram showing the axonal projection from the PcSG neuron to the salivary glands. Different colors of nuclei in $\mathbf{B}$ and $\mathbf{C}$ indicate different types of cells based on their size and shape in the confocal image (purple, neck cells; blue, basal granular cells; green, apical granular cells; pink, epithelial cells in B; purple, neck cells; blue, basal granular cells; aqua blue, basal cells; greenish gray, apical cells; pink, epithelial cells in C. Note that only acini II and III are innervated, whereas MIP/SIFamide innervation was never observed in acini I. Four or five axonal branches in acini II and three or four branches in acini III are in contact with the basal cells that have large, round nuclei. See nomenclature of peptidergic neurons and list of Abbreviations. 
A

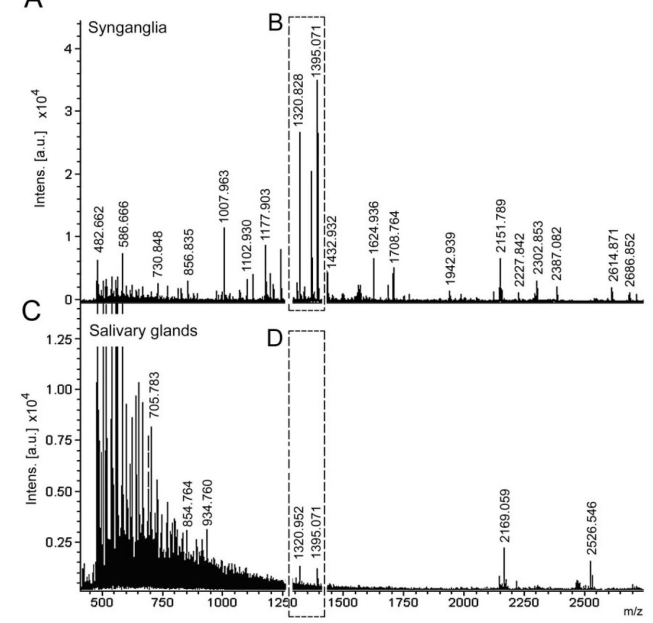

B

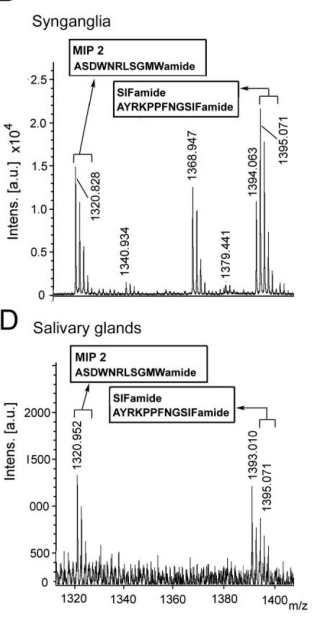

Figure 8.

MALDI-TOF mass spectra of synganglia extract (A) and salivary gland extract (C). The insets in $(\mathbf{A}, \mathbf{C})$ are magnified in $(\mathbf{B}, \mathbf{D})$. Two large peaks, $[\mathrm{M}+\mathrm{H}]^{+}$1,395.07 and 1,320.94, were commonly observed in both extracts. Spectra were measured using accumulation at 200 laser shots per second with conditions optimized for the detection of m/z 400-3,000 Da. 


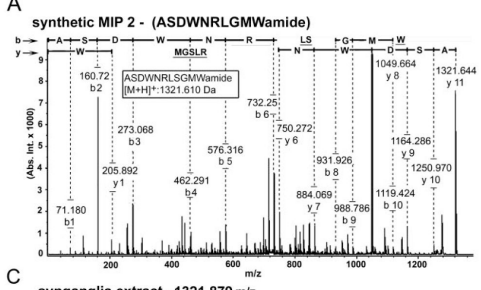

C

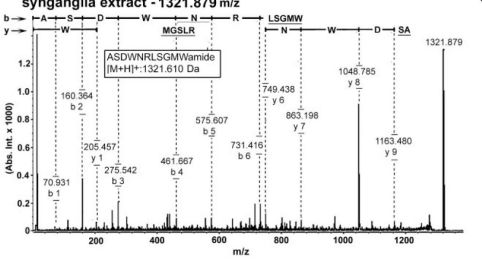

synthetic SIFamide - (AYRKPPFNGSIFamide)

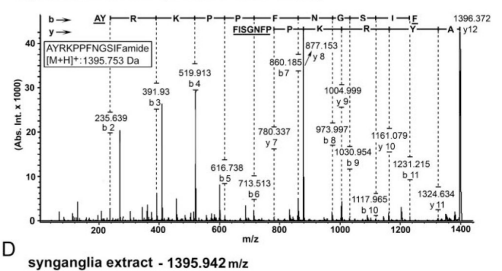

synganglia extract - $1395.942 \mathrm{~m} / \mathrm{z}$

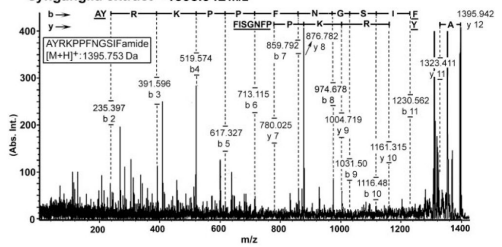

Figure 9.

MALDI-TOF tandem mass spectrometry spectra for the MIP2 and SIFamide peptides. The spectra in fragmentations of MIP2 synthetic peptide (A) and in the fragmentations of the $\mathrm{m} / \mathrm{z}$ 1,322 peak in the synganglia extract $(\mathbf{C})$ show nearly identical profiles, supporting the MIP2 sequence ASDWNRLSGMWamide. The spectra in fragmentations of the SIFamide synthetic peptide (B) and in the fragmentations of the $\mathrm{m} / \mathrm{z}$ 1,396 peak in the synganglia extract (D) show nearly identical profiles, supporting the SIFamide sequence AYRKPPFNGSIFamide. Several $b$ - and $y$-type fragments were labeled. Underscored fragments were not detectable with tolerance 1.5 in the Flex Analysis 3.0 software. 
TABLE 1

Antibodies Used in This Study

\begin{tabular}{lcccc}
\hline Antibody name & Host & Dilution & Source/characterization & Immunogen \\
\hline Manse MIP I & Mouse monoclonal & $1: 1,000$ & Kim et al., 2006 & AWQDLNSAWamide $^{1}$ \\
Drome SIFamide & Rabbit polyclonal & $1: 1,000$ & Terhzaz et al., 2006 & AYRKPPFNGSIFamide $^{2}$ \\
\hline
\end{tabular}

${ }^{1}$ See Figure 1 for sequence comparison.

${ }^{2}$ See Figure 2 for sequence comparison. This sequence is identical to the SIFamide of I. scapularis. 